\title{
Epidemiology of periodontal disease in adolescents in mainland China, 1983-2020: a systematic review and meta-analysis
}

\author{
Li Xiao ${ }^{1,2,3,4}$, Kalen Karapen ${ }^{1,2,3}$, Shi Dong ${ }^{1,2,3}$, Hongmei Yang ${ }^{1,2,3}$, Xiaonan Zhang ${ }^{1,2,3}$ \\ ${ }^{1}$ College of Stomatology, Chongqing Medical University, Chongqing, China; ${ }^{2}$ Chongqing Key Laboratory of Oral Diseases and Biomedical Sciences, \\ Chongqing, China; ${ }^{3}$ Chongqing Municipal Key Laboratory of Oral Biomedical Engineering of Higher Education, Chongqing, China; ${ }^{4}$ The First \\ Affiliated Hospital of Chongqing Medical University, Chongqing, China \\ Contributions: (I) Conception and design: L Xiao, X Zhang; (II) Administrative support: X Zhang; (III) Provision of study materials or patients: S \\ Dong; (IV) Collection and assembly of data: S Dong, K Karapen; (V) Data analysis and interpretation: L Xiao, H Yang; (VI) Manuscript writing: All \\ authors; (VII) Final approval of manuscript: All authors. \\ Correspondence to: Xiaonan Zhang. College of Stomatology, Chongqing Medical University, Chongqing, China, No. 426 Songshibei Road, Yubei \\ District, Chongqing, China. Email: zhangxiaonan@hospital.cqmu.edu.cn.
}

\begin{abstract}
Background: Periodontal disease is a chronic inflammatory disease that includes primarily gingivitis and periodontitis, caused by bacterial infection of the supporting structures of the teeth. For years, much attention has been diverted to periodontal disease among the elderly, not enough attention is paid to adolescents. The purpose of this meta-analysis is to evaluate the epidemic trend of periodontal disease in adolescents in mainland China.

Methods: We conducted a comprehensive literature search through PubMed, Embase, CNKI, Chongqing VIP database, Chinese Wan Fang Database, and CBM. A series of subgroup analyses were done to explore the epidemiological characteristics of periodontal disease (gender, location, age, survey year, and geographical distribution) with the help of related software.

Results: Thirty studies were included in this study. The data extraction and analysis were from three indexes, including bleeding on probing (BOP), pocket depth (PD), and dental calculus (DC). The detection rates of $\mathrm{BOP}(+), \mathrm{PD} \geq 4 \mathrm{~mm}$ and $\mathrm{DC}(+)$ were $48.8 \%$ (95\% CI: $36.2-61.4 \%), 1.0 \%(0.0-2.0 \%)$, and $49.8 \%$ (41.0-58.6\%), respectively. There were significant differences for the prevalence of gingivitis both in gender and area: the prevalence was higher in males than that in females, and risk ratio was 1.04 (95\% CI, 1.01-1.06); a lower prevalence in urban areas compared with rural areas, and the risk ratio was 0.90 (95\% CI, 0.85-0.96).

Conclusions: This study shows a high prevalence of gingivitis among adolescents in China. Higher-quality epidemiological surveys with standard examination criteria are needed.
\end{abstract}

Keywords: Epidemiology; periodontal disease; adolescents; systematic review

Submitted Aug 17, 2020. Accepted for publication Dec 23, 2020.

doi: 10.21037/apm-20-1919

View this article at: http://dx.doi.org/10.21037/apm-20-1919

\section{Introduction}

Periodontal disease is a chronic inflammatory disease that includes primarily gingivitis and periodontitis, caused by bacterial infection of the supporting structures of the teeth (1). For years, much attention has been diverted to periodontal disease among the elderly $(2,3)$, not enough attention is paid to adolescents. However, periodontal disease is among the most common diseases affecting adolescents (4). Gingivitis in adolescents may remain for a more extended period with the symptom of gingival bleeding, and it may gradually lead to the progression of periodontitis. However, according to WHO Global Oral Health Data Bank, the occurrence of periodontal disease is high among older children and adolescents, with $50 \%$ to $100 \%$ of 12 -year-old children having the signs of gum inflammation (5), this suggests a 
risk of periodontal disease among the adolescent population. Periodontal disease may have negative effects on oral health, chewing function, and aesthetics, and the physical and mental health of adolescents (6). Also, it has been reported that periodontal disease may influence the severity of malocclusion in adolescents $(7,8)$.

Earlier studies have reported the different disease burden of periodontal diseases among adolescents worldwide. For instance, the prevalence of chronic periodontitis among $15-19$ years old in Asia differs, including $0 \%$ in India (9) and $6 \%$ in Japan (10); a higher prevalence in Africa, which includes Algeria (13\%) (11), Egypt (17\%) (11) and Nigeria $(56 \%)(11)$. As for gingivitis among the adolescents aged 15 , the prevalence rates varied according to national oral health surveys in different countries, ranging from $30 \%$ in Greek (12), 16\% in the United Arab Emirates (13), and $52 \%$ in the United Kingdom of Great Britain and Northern Ireland (14). China is the most populous country in the world, with a vast territory, considerable differences in income, and traditions. The total population of adolescents was around 174 million in 2010 , adding up to $13.11 \%$ of the national population (15). Several studies have reported the prevalence of the periodontal disease in adolescents in mainland China, which showed a significant difference. For instance, the reported prevalence of gingivitis at age 15 years was about $5.75 \%$ in Heilongjiang (16), while $87.6 \%$ in Hubei (17). These differences may be because of different survey sites, survey methods, and diagnostic criteria.

There are no systematic reviews on the prevalence of the periodontal disease in adolescents in mainland China. Therefore, adolescents aged 10-19 years were selected for this study (18). We analyzed the epidemiological characteristics of periodontal disease in adolescents from all cross-sectional studies in this meta-analysis to explore the prevalence trend with time, gender, age, and geography. These results may supply valuable information to prevent periodontal disease and implementing relevant oral health policies for adolescents.

We present the following article in accordance with the PRISMA reporting checklist (available at http://dx.doi. org/10.21037/apm-20-1919).

\section{Methods}

\section{Search strategy}

A comprehensive electronic search was conducted in PubMed and Embase and Chinese databases, including the Chinese
National Knowledge Infrastructure Database (CNKI), Chongqing VIP database, Chinese Biomedical Literature Database (CBM), and Chinese Wan Fang Database, by two independent authors. The electronic search was conducted for articles from commencement to 2 February 2020, using the key terms 'periodontitis', 'periodontal disease,' 'prevalence,' 'incidence,' 'epidemiology,' 'epidemiologic,' 'China' and 'Chinese.' Also, a manual search was done for potential literature to avoid the loss of information.

\section{Literature selection}

All screening procedures and reporting of this meta-analysis followed the guidance of Preferred Reporting Items for Systematic Reviews and Meta-Analyses (PRISMA) (19). The two authors reviewed the titles and abstracts of relevant literature independently, and full-text articles of the potentially available literature were analyzed. Discrepancies were resolved by discussion or by the third author, and Cohen's Kappa values were used to determine the agreement level between the reviewers (20).

Inclusion criteria: the articles selected in this study were according to the following inclusion criteria; (I) surveys done in mainland China (except Hong Kong, Taiwan, and Macao); (II) participants within the age of 10-19 years old; (III) the survey areas were city-level or above; (IV) studies containing adequate information for diagnosing periodontal disease and calculating the relative prevalence; (V) articles published in English or Chinese; (VI) studies with the random sampling method.

Exclusion criteria: the articles excluded were: (I) studies carried out on particular population or areas; (II) survey sites below city-level; (III) study population younger than ten years old and older than 19 years old; (IV) repeated literature; (V) low-quality literature, secondary studies or irrelevant studies.

\section{Data extraction}

Two authors carried out the data extraction independently, and the following data were extracted: survey year, regional level, survey location, age range, sampling methods, methods and criteria used for diagnosis, number of samples, and cases (total, males or females, urban or rural). All data were from the detection rates of dental calculus (DC)(+), bleeding on probing $(\mathrm{BOP})(+)$, and pocket depth $(\mathrm{PD}) \geq 4 \mathrm{~mm}$. The Community Periodontal Index of Treatment Needs (CPITN) or Community Periodontal Index (CPI) examination 
retrieved the measured variables in most of the studies. Other studies did not show the examination performance method. Two extraction sheets were also completed independently by the two investigators to confirm the accuracy and feasibility of the data extraction. Disagreements were resolved by consensus or by the third author.

\section{Quality assessment}

The qualities of the included studies were assessed by applying the 'Strengthening the Reporting of Observational Studies in Epidemiology (STROBE)' statement (21) (Table S1). Six items were used in the STROBE checklist, which included evaluations of the title and abstract, introduction, methods, results, discussion, and other information. The checklist was assessed independently by the two investigators, and an agreement was reached, or the third author was consulted when necessary.

\section{Data analysis}

The pooled detection rates and $95 \%$ confidence intervals (CI) for each indicator were estimated via $\mathrm{R}$ software version 3.3.3. $\mathrm{I}^{2}$-statistics was applied to explore the statistical heterogeneity across the included studies. A random-effects model was selected if the heterogeneity was significant $\left(\mathrm{I}^{2}>50 \%\right.$ or $\left.\mathrm{P}<0.05\right)$. When there was less heterogeneity, a fixed-effects model was adopted. A series of subgroup analyses were done by two authors to explore the relationship between the detection rates with some factors, including gender, age, and location. $\mathrm{R}$ software version 3.3.3 and STATA software 16.0 were combined to calculate relative risk (RR) and $95 \% \mathrm{CI}$ to compare discrepancies. Graph Pad Prism was used to describe the trends within different periods $(\leq 1990,1991-1995,1995-2000,2001-$ 2005, 2006-2010, and $\geq 2011$ ) or the different ages (12, 15,18 years old). SuperMap GIS software 2.0 was used to present the regional distribution of detection rates. Funnel plots and Begg's test estimated publication bias. The level of statistical significance was set at 0.05 . Sensitivity analysis was performed to detect effects on conclusions of statistical analysis by eliminating each study.

\section{Results}

\section{Literature selection and quality assessment}

A preliminary result of 5,922 studies were identified, including PubMed ( $\mathrm{n}=537)$, Embase $(\mathrm{n}=385)$, CNKI $(n=1,345)$, the Wan Fang Database $(n=1,549)$, the Chongqing VIP Database ( $\mathrm{n}=1,147)$, and CBM ( $\mathrm{n}=959)$. Subsequently, 3,050 studies were excluded after adjustment of duplicates, and 2,109 studies were discarded after browsing the titles and the abstracts. After examining the full texts of 763,314 studies on special populations or the surveys were conducted in special areas; 13 survey sites are below city-level; 2 did not report survey data; 34 did not report survey site and survey time; 296 did not report age clearly, or age was younger than 11 , or age was older than 20; 45 literatures are low quality; 29 did not relevant. From the 763 full-text articles retrieved, only 30 studies met the eligibility criteria (Figure 1) and were included in this review. Of the 30 included studies, 4 epidemiological surveys (16,22-24), 25 were published in Chinese (17,25-48), and only one was in English (49). These articles included three national level, seven provincial-level, and 20 city-level. The Kappa values for titles and abstracts screening was 0.864, and for full-text evaluation was 0.804 (Tables S2,S3).

The detailed characteristics of the 30 included studies are presented in Table 1. Twenty-one articles followed random sampling, while the others do not mention the sampling methods. Professional dentists and medical students were recruited as examiners in 19 studies and were trained to achieve unified criteria of examination methods and diagnostic indexes.

There were different diagnostic criteria in the included studies (Table 1). The diagnostic indexes were with BOP, $\mathrm{DC}$, and PD. The examination methods also differed, in which 22 studies used the CPITN (50) or CPI (51). In these methods, only six index teeth $(11,16,26,31,36,46)$ are examined, and the results of PD in participants under 15 years old are not recorded to avoid the false periodontal pocket formed during the eruption of permanent teeth (52). One study examined all the teeth of the subjects, and seven studies did not indicate the examination methods used.

The Strobe checklist estimated quality assessment, and 32 listed items scored each study/sub-items. The results showed favorable outcomes and were of acceptable quality (Table S4).

\section{Detection rates of $\mathrm{BOP}(+)$}

Twenty-six studies reported the detection rates of $\mathrm{BOP}(+)$, and the detection rate was $48.8 \%$ (95\% CI: $36.2-61.4 \%$ ).

$\mathrm{BOP}(+)$ detection rates by gender. Detection rates of $\mathrm{BOP}(+)$ by gender was indicated in 21 articles. The detection 


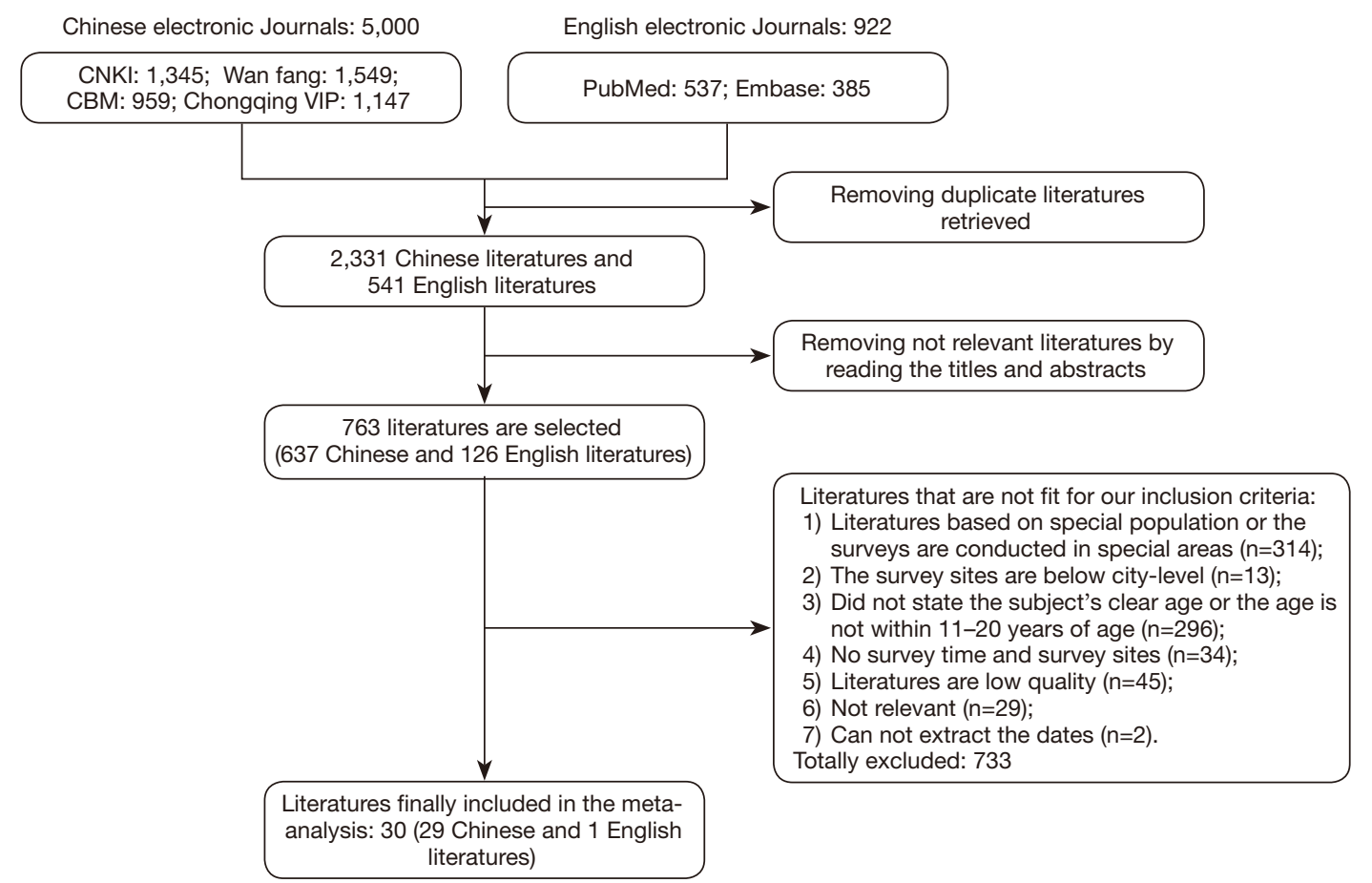

Figure 1 Flow chart showing the meta-analysis studies selection.

rates in males was $51.0 \%$ (95\% CI: 35.9-66.1\%) while in females was $48.7 \%$ (95\% CI: 34.7-62.8\%, Table 2). A significant result revealed that the detection rate of $\mathrm{BOP}(+)$ in males was higher than that in females ( $\mathrm{RR}=1.04,95 \%$ CI: 1.01-1.06, Figure 2A).

$\mathrm{BOP}(+)$ detection rates by location. 12 studies reported $\mathrm{BOP}(+)$ both in urban and rural areas. Respectively, the pooled detection rates in urban and rural areas were $46.4 \%$ (95\% CI: $32.0-60.8 \%$ ) and $46.3 \%$ (95\% CI: $28.1-64.5 \%$, Table 2). The detection rate of $\mathrm{BOP}(+)$ in urban areas was lower than that in rural areas ( $\mathrm{RR}=0.90,95 \%$ CI: 0.85-0.96, Figure $2 B$ ).

$\mathrm{BOP}(+)$ detection rates with survey year. Table 2 shows the pooled detection rates of $\mathrm{BOP}(+)$ for surveys done in $\leq 1995$, 1995-2000, 2001-2005, 2006-2010 and $\geq 2011$ were $82.2 \%$ (95\% CI: $39.4-100.0 \%$ ), $47.0 \%$ (95\% CI: $26.2-67.9 \%$ ), $35.7 \%$ (95\% CI: $11.0-60.4 \%$ ), $46.3 \%$ (95\% CI: 22.0 $70.6 \%$ ) and $44.8 \%$ (95\% CI: $25.4-64.3 \%$ ), respectively. No significant trend is reflected from 1983 to 2020 (Figure 2C).

$\mathrm{BOP}(+)$ detection rates by age group. The detection rate of $\mathrm{BOP}(+)$ was $53.2 \%$ (95\% CI: 36.7-69.7\%) in adolescents aged 12 as reported in 12 studies. Eleven studies reported the detection rates for aged 15 , while the detection rates for the 18 years old were shown in six studies. The results were $39.8 \%$ (95\% CI: $21.5-58.0 \%$ ) and $36.2 \%$ (95\% CI:
$12.1-60.3 \%)$ respectively. We observed a decreasing trend of prevalence with individuals aged from 12 to 18 .

\section{Detection rates of $P D \geq 4 \mathrm{~mm}$}

The pooled estimated detection rate of PD in 13 studies (15-19 years old) conducted from 1983 to 2020 was $1.0 \%$ (95\% CI: $0.0-2.0 \%$ ), as shown in Table 2. PD $\geq 4 \mathrm{~mm}$ detection rates by gender. 12 studies reported the detection rates in males and the pooled detection rate was 1.0\% (95\% CI: $0.0-3.0 \%$ ), while the pooled detection rate was $1.0 \%$ (95\% CI: $0.0-3.0 \%$, Table 2). The results show no difference in subgroup analysis with gender ( $\mathrm{RR}=1.05,95 \% \mathrm{CI}$ : 0.97 1.13 , Figure $3 A$ ).

$\mathrm{PD} \geq 4 \mathrm{~mm}$ detection rates by location. The detection rates in urban areas were reported in 11 studies, while three studies were reported for rural areas. Respectively, the detection rates of PD $\geq 4 \mathrm{~mm}$ in urban areas were $1.0 \%$ (95\% CI: 0.0 $3.0 \%$ ), and $2.0 \%$ (95\% CI: $0.0-8.0 \%$, Table 2) in rural areas. Statistically, no significant difference was shown in these two groups by area (RR $=0.95,95 \%$ CI: $0.83-1.08$, Figure $3 B$ ).

$\mathrm{PD} \geq 4 \mathrm{~mm}$ detection rates with survey year. The detection rates of $\mathrm{PD} \geq 4 \mathrm{~mm}$ during 2001-2005 were not available, and the detection rates in $\leq 1995,1996-2000$, 


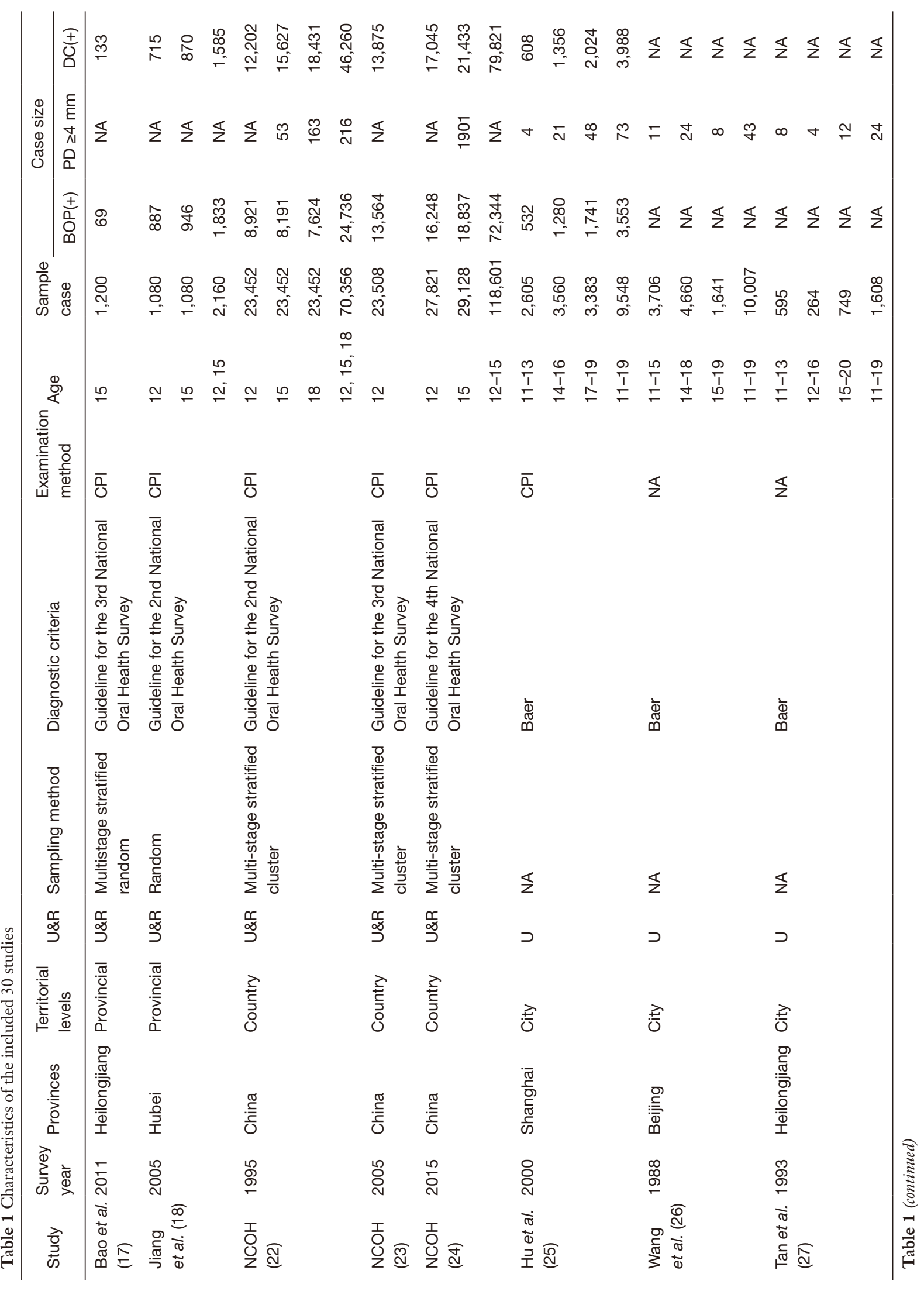




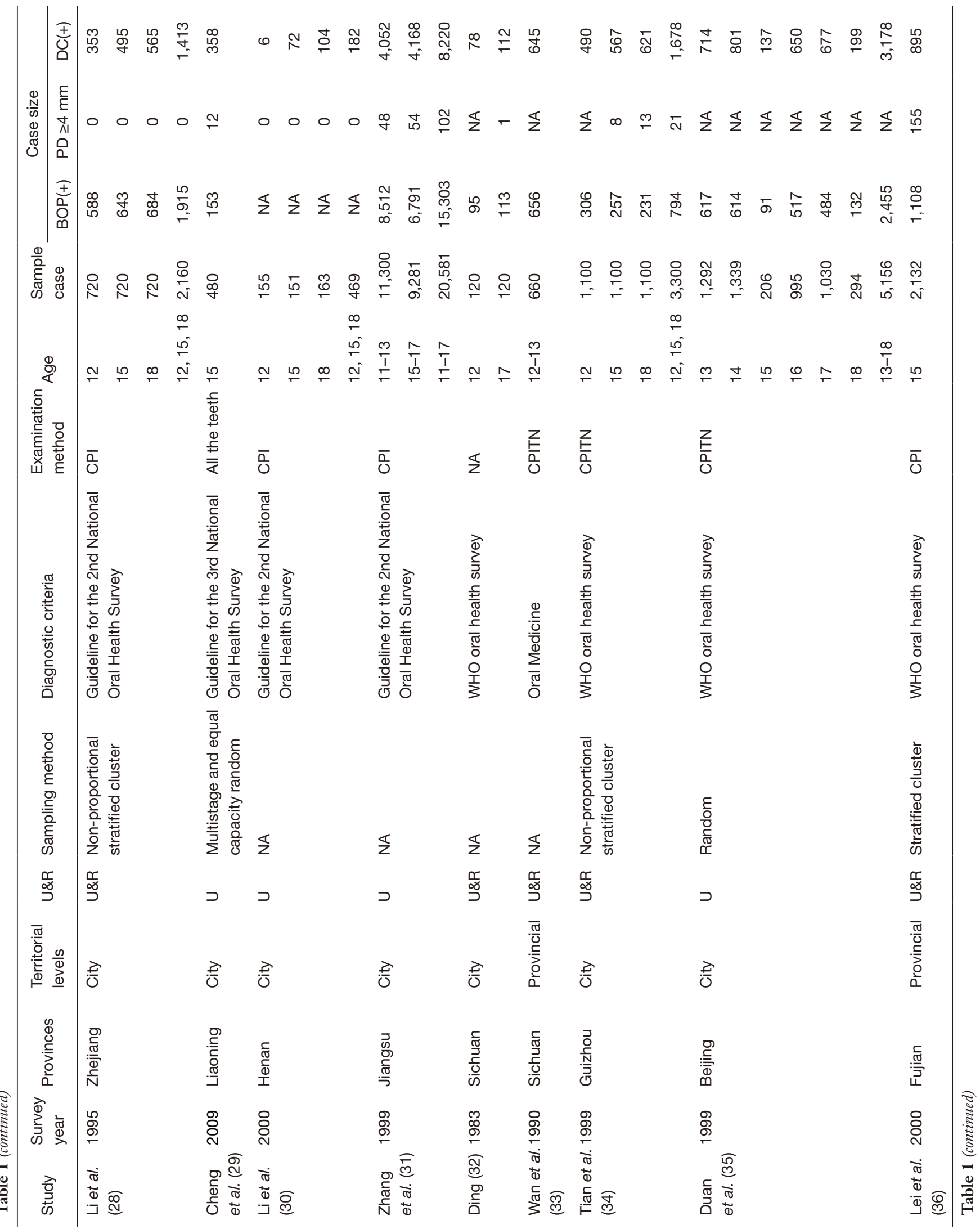




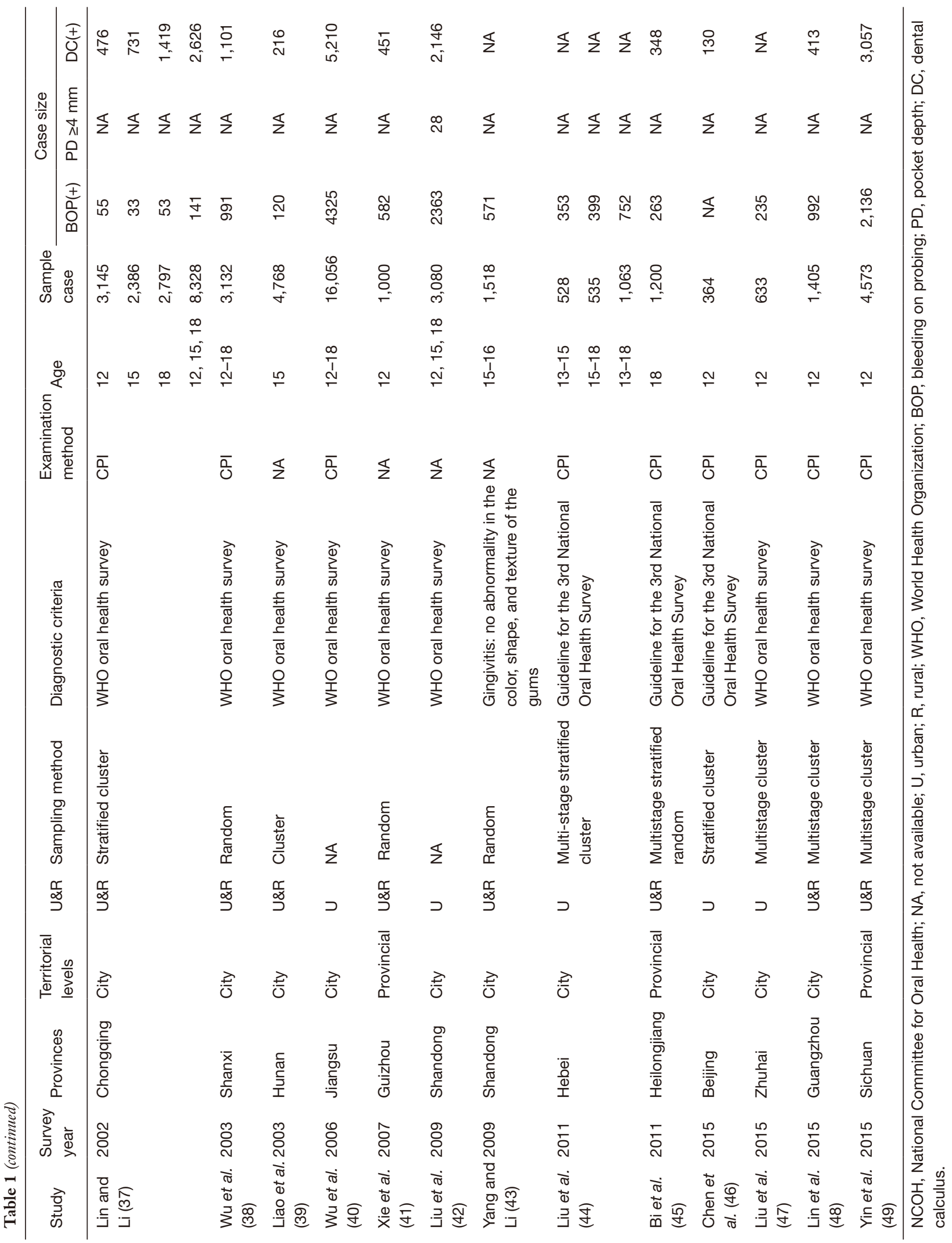




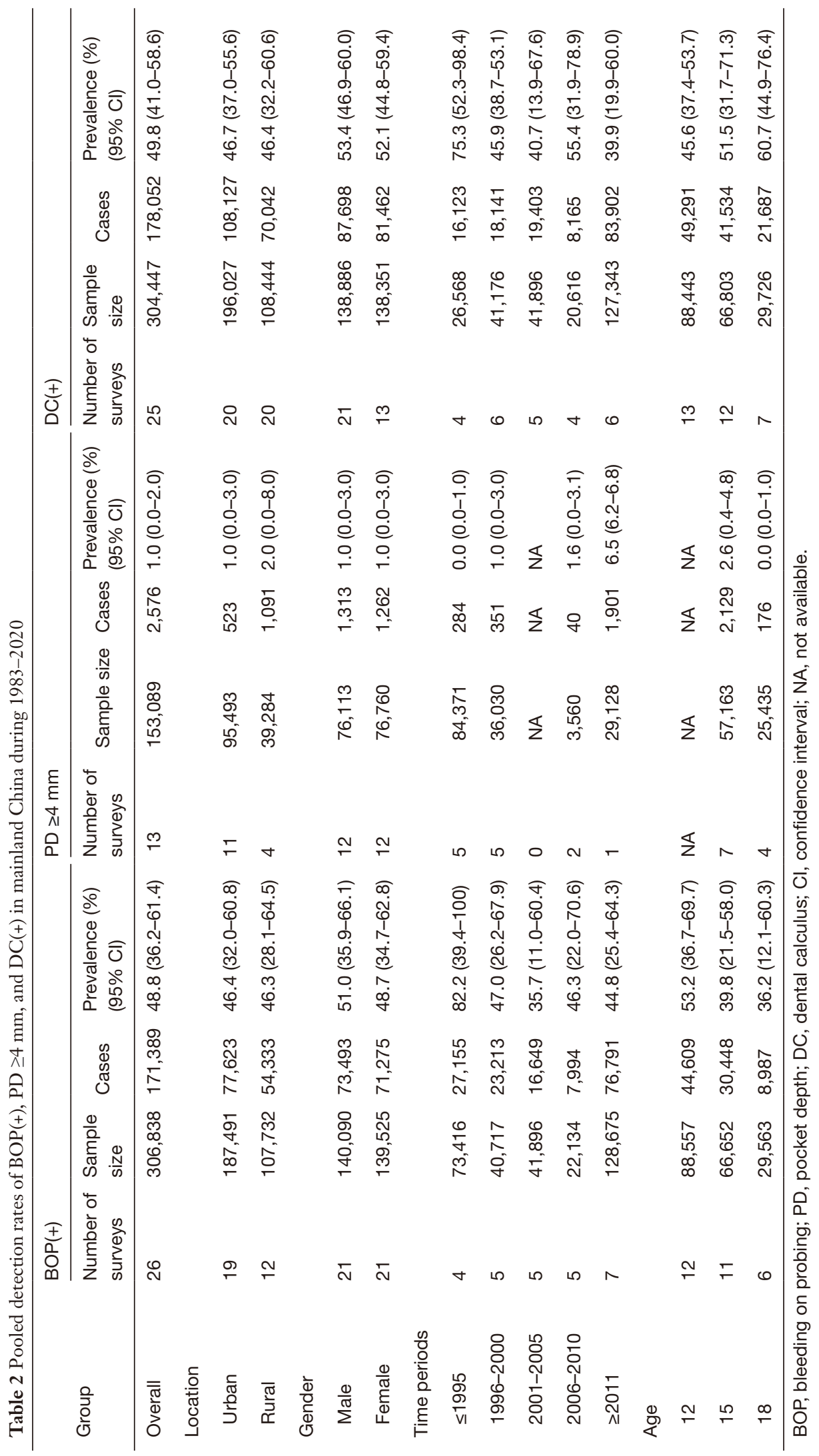




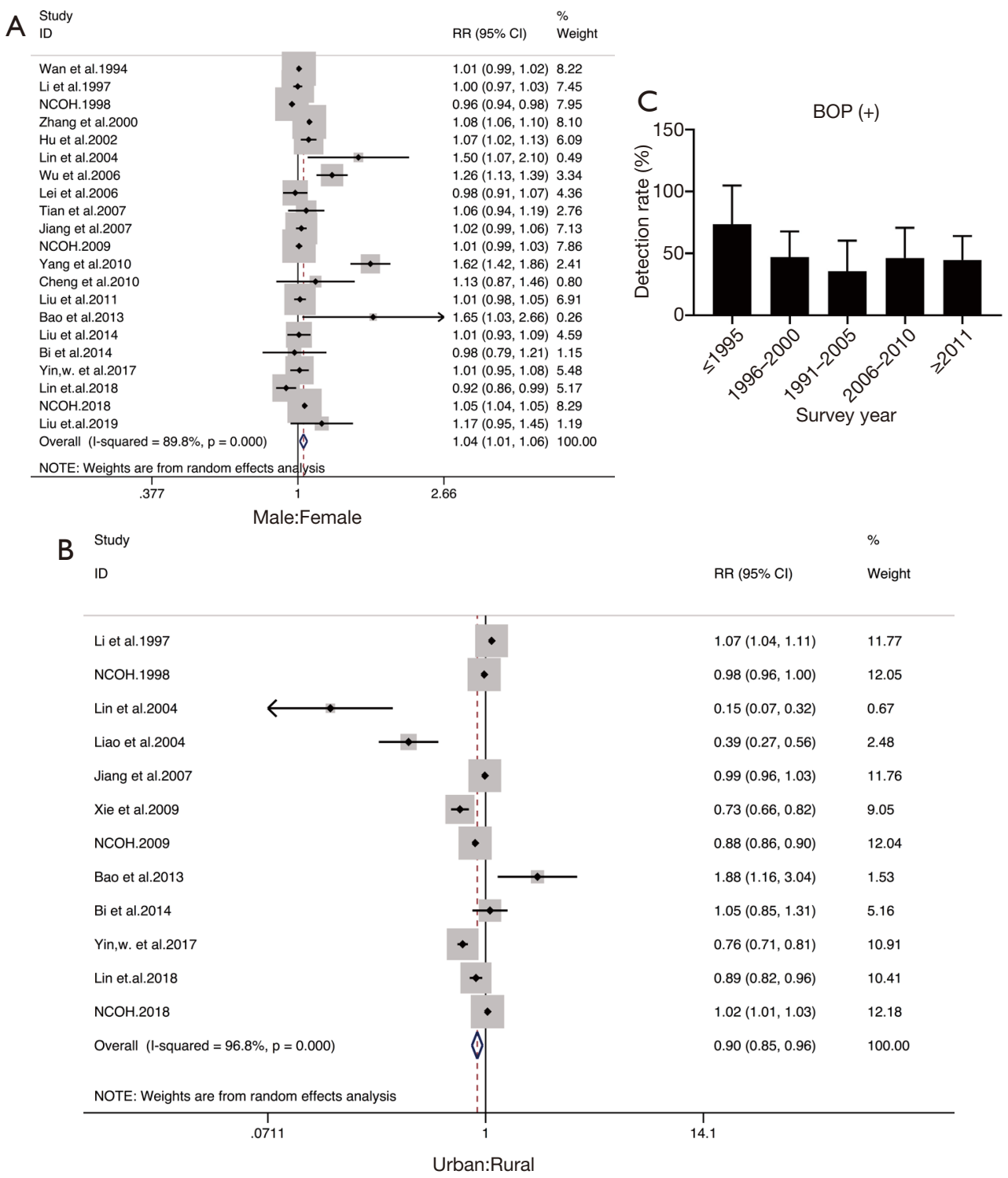

Figure 2 The detection rates of BOP among adolescents in mainland China during 1983-2020. BOP, bleeding on probing.

2006-2010 and 1996 were $0.0 \%$ (95\% CI: $0.0-1.0 \%), 1.0 \%$ (95\% CI: $0.0-3.0 \%$ ), $1.6 \%$ (95\% CI: $0.0-3.1 \%$ ) and $6.5 \%$ (95\% CI: 6.2-6.8\%). An increasing trend is observed from 1983 to 2020 (Figure 3C).

$\mathrm{PD} \geq 4 \mathrm{~mm}$ detection rates by age group. The detection rates of PD were $2.6 \%$ (95\% CI: $0.4-4.8 \%$ ) in adolescents at age 15 and $0.0 \%$ (95\% CI: $0.0-1.0 \%$ ) at age 18 . There is no significant trend with age from 15 to 18 years old.

\section{Detection rates of $\mathrm{DC}(+)$}

Twenty-five publications reported DC detection rates, and the pooled detection rate was $49.8 \%$ (95\% CI: $41.0-58.6 \%)$.

$\mathrm{DC}(+)$ detection rates by gender. 20 studies showed detection rates by gender, in which $53.4 \%$ (95\% CI: 46.9$60.0 \%$ ) in males and $52.1 \%$ (95\% CI: 44.8-59.4\%, Table 2) in females. There were no obvious statistical differences in these two groups (RR =1.03, 95\% CI: 0.98-1.07, Figure 4A).

$\mathrm{DC}(+)$ detection rates by location. As shown in Table 2, 21 studies reflected the detection rates of $\mathrm{DC}(+)$ in urban areas and 13 studies in rural areas. The detection rates in urban and rural areas were 46.7\% (95\% CI: 37.9-55.6\%, Table 2) and $46.4 \%$ (95\% CI: 32.2-60.6\%, Table 2), respectively. There was a slight difference between urban 


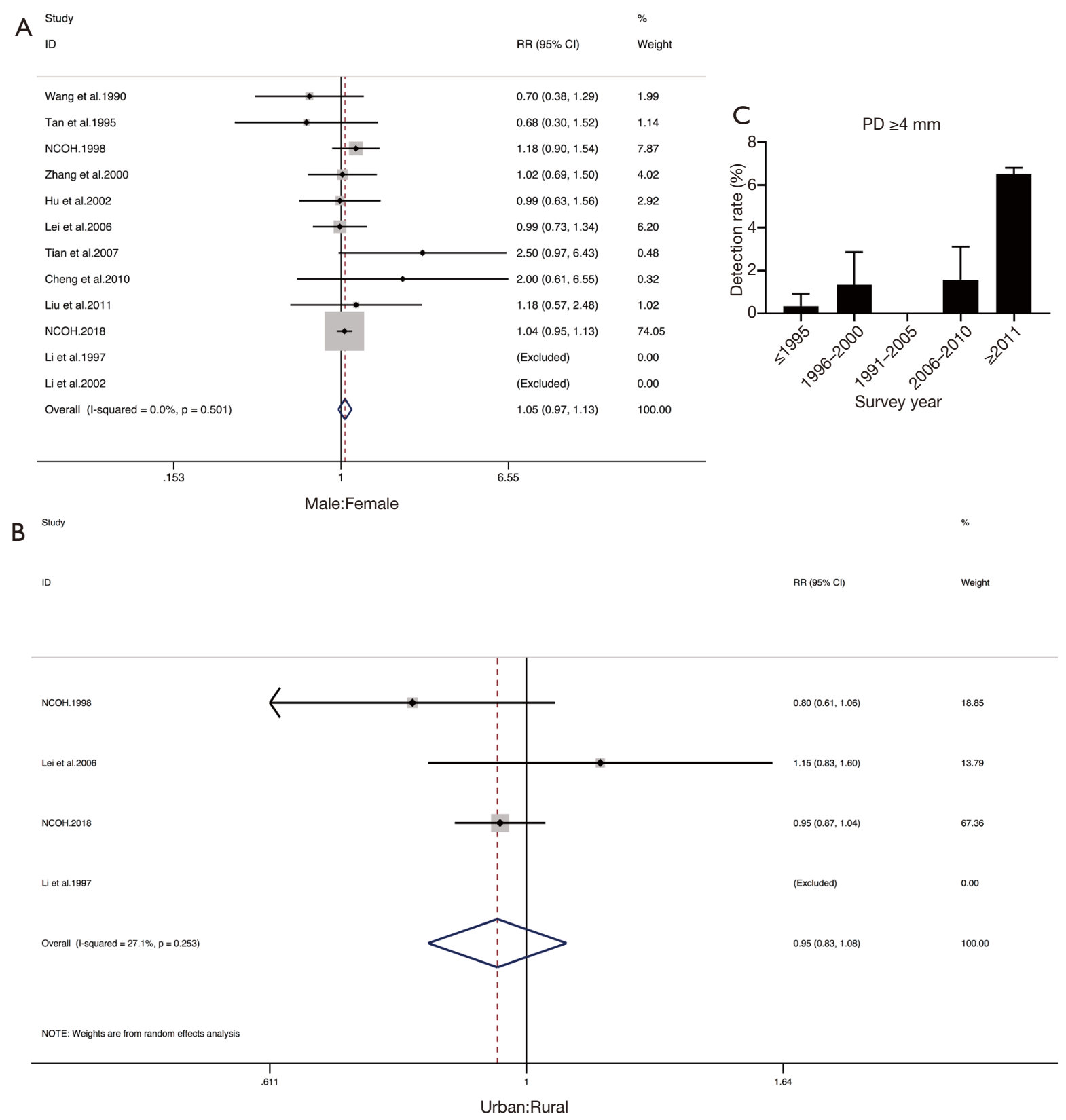

Figure 3 The detection rates of PD among adolescents in mainland China during 1983-2020. PD, pocket depth.

and rural areas ( $\mathrm{RR}=0.96,95 \% \mathrm{CI}, 0.91-1.02)$ (Figure $4 B)$.

$\mathrm{DC}(+)$ detection rates from survey year. Table 2 shows the pooled detection rates of $\mathrm{DC}(+)$ in surveys done in $\leq 1995$, 1995-2000, 2001-2005, 2006-2010 and $\geq 2011$ were $75.3 \%$ (95\% CI: $52.3-98.4 \%$ ), $45.9 \%$ (95\% CI: $38.7-53.1 \%$ ), 40.7\% (95\% CI: $13.9-67.6 \%$ ), 55.4\% (95\% CI: $31.9-$ $78.9 \%$ ), and $39.9 \%$ (95\% CI: $19.9-60.0 \%)$, respectively. The detection rate of DC in adolescents reflects a fluctuating trend from 1983 to 2020 (Figure 4C).
$\mathrm{DC}(+)$ detection rates by age group. The detection rates of DC were $45.6 \%$ (95\% CI: 37.4.4-53.7\%) at aged 12, $51.5 \%$ (95\% CI: $31.7-71.3 \%$ ) at aged 15 , and $60.7 \%$ (95\% CI: $44.9-76.4 \%)$ at aged 18 , respectively. The result reflects an elevated rate as age increases.

\section{Regional distribution of detection rates in mainland China}

The color-coded map in Figure 5 illustrates the distribution 


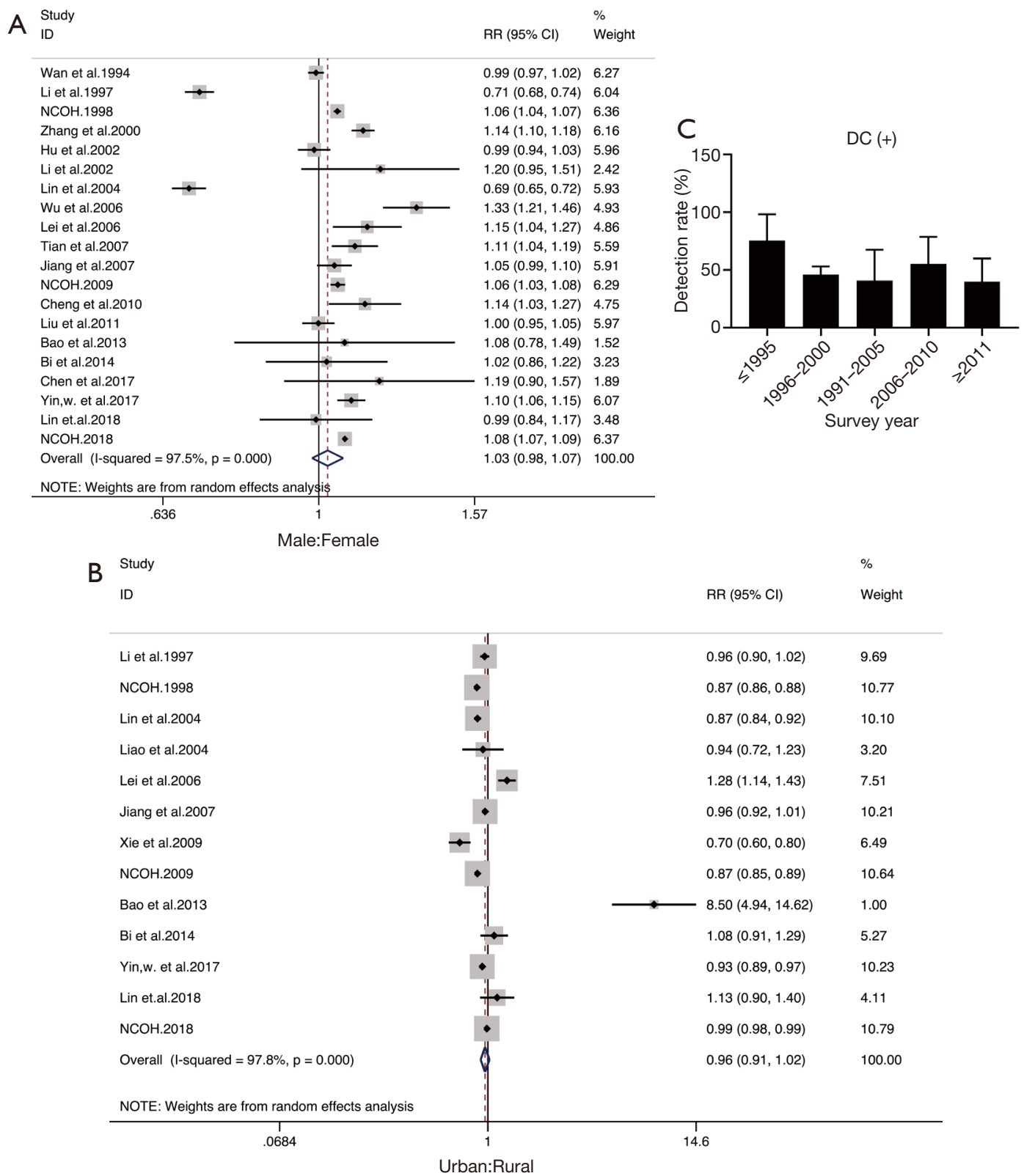

Figure 4 The detection rates of DC among adolescents in mainland China during 1983-2020. DC, dental calculus.

of the detection rates of $\mathrm{BOP}(+), \mathrm{PD} \geq 4 \mathrm{~mm}$, and $\mathrm{DC}(+)$ in mainland China, respectively (except Tibet). Five distribution zones on the map with distinct colors were created. The first level shows that there is no available data in the relevant regions and is white on the map. The second to fourth levels are arranged by detection rate from low to high, and the color on the map is from light to deep. The highest detection rate is shown at the highest level, which is dark red on the map. The detection rates of $\mathrm{BOP}(+)$ ranged from $98.6 \%$ in Qinghai to $11.3 \%$ in Yunnan. The detection rate of $\mathrm{PD} \geq 4 \mathrm{~mm}$ was highest in Fujian $(7.2 \%)$ and lowest in Hunan $(0.0 \%)$. The detection rates of DC had significant differences in various regions, ranging from $89.4 \%$ in Qinghai to $37.4 \%$ in Heilongjiang. No features in the distribution of $\mathrm{BOP}(+), \mathrm{PD} \geq 4 \mathrm{~mm}$, and $\mathrm{DC}(+)$ detection rates are presented on the map.

\section{Publication bias and sensitivity test}

The funnel plots show publication bias, and the results of 
A

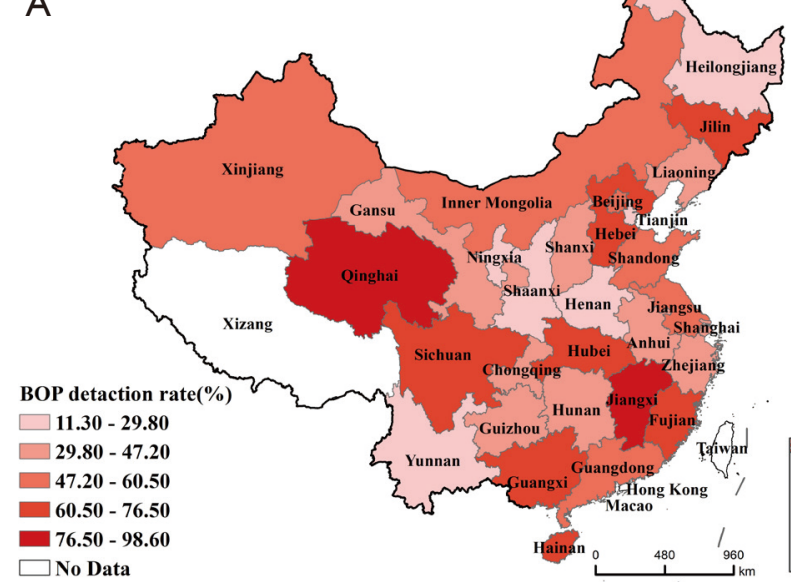

$\square$ No Data

C

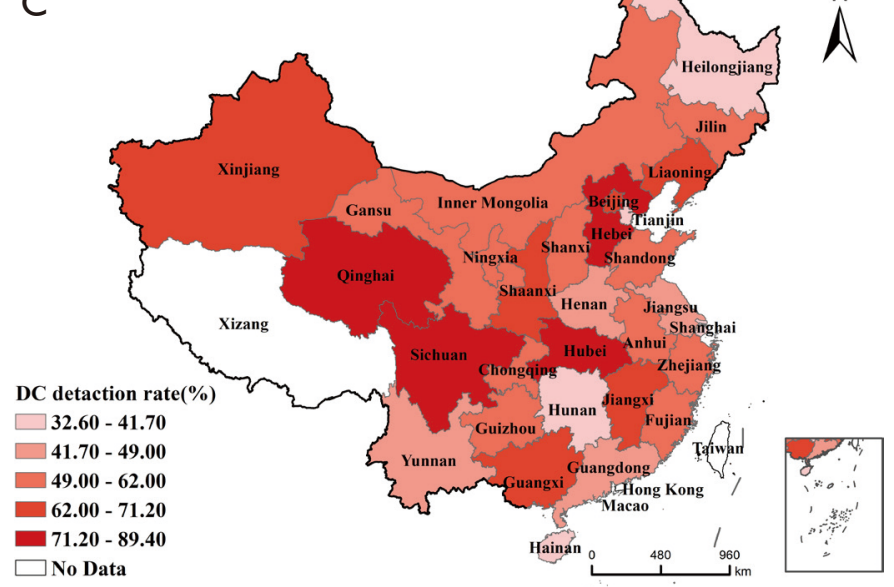

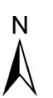

B
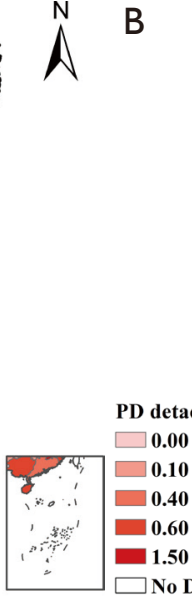

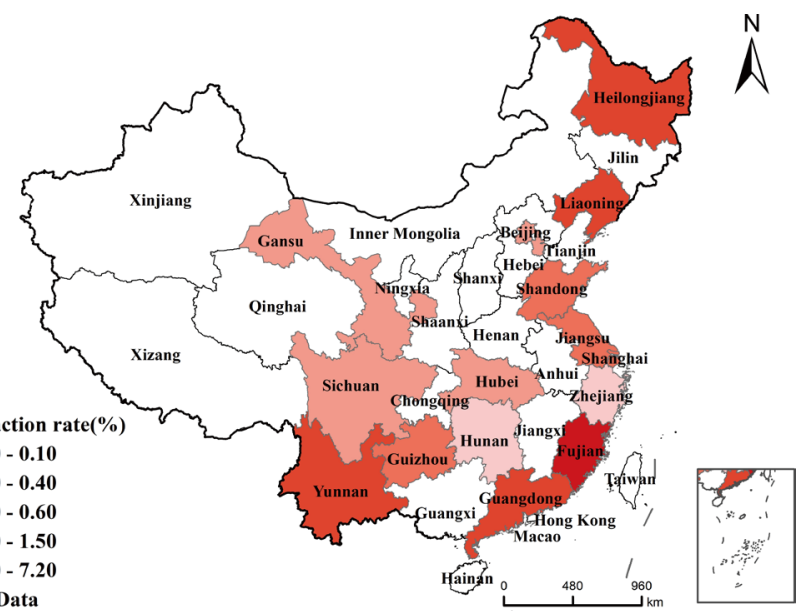

$1.50-7.20$
$\square$ No Data

$\square 0.00-0.10$

$0.10-0.40$

$0.60-1.50$

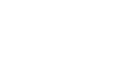

Figure 5 Regional distribution of detection rates of periodontal disease among adolescents in mainland China.

the three indexes were asymmetric (Figure S1). Beyond that, Begg's tests also suggest publication bias $(\mathrm{P}<0.001)$. A sensitivity analysis was conducted by eliminating each study to detect changes in conclusions of statistical analysis (53). After eliminating each study, the conclusions of statistical analysis are not influenced, which means the robustness of results.

\section{Discussion}

This study aims to present the epidemic trend of periodontal disease in adolescents in China. Periodontal disease is considered a common disease among the elderly. Further, the prevalence rate of gingivitis among the elderly in China is $57.9 \%$ (2). The results showed that the prevalence rate of gingivitis among adolescents estimated by $\mathrm{BOP}(+)$ was $48.8 \%$, so the periodontal situation of adolescents should not be ignored, which was reported to be $20 \%$ in South Australia (54), 34.9\% in Italy (55), and $14 \%$ in Japan (11). These differences in the results of gingivitis prevalence may be related to better oral hygiene and related consciousness in developed countries $(56,57)$. In this review, only 13 studies reported the detection rate of $\mathrm{PD} \geq 4 \mathrm{~mm}$, the prevalence rate of gingivitis among adolescents estimated by $\mathrm{PD} \geq 4 \mathrm{~mm}$ was $1 \%$, an increasing trend is observed from 1983 to 2020 . Therefore, a prompt periodontal examination of adolescents is essential.

In the adolescent population, oral epidemiological surveys usually focus on dental caries, and there are few reports on periodontitis. For instance, the national oral health surveys in the United States (58) and South Australia (54) reported only the prevalence of dental caries, DC, or gingival bleeding in adolescents, with no reference to periodontitis in adolescents. The detection rates of PD 
$\geq 4 \mathrm{~mm}$ at the population over 15 years old, for avoiding the false pockets formed during the eruption of permanent teeth, suggested by Petersen et al. (52). This is one reason there are fewer reports of periodontitis in adolescents. However, among the included studies, seven studies (25-31) examined the PD of participants under 15 years old, and four $(25,26,28,30)$ reported positive results. PD examination is vital for young people under the age of 15 . Hence, the improvement of the examination method is beneficial for the diagnosis of periodontitis and the identification of false periodontal pockets. Attempts can be made to examine the PD regularly when finding deep periodontal pockets. Jenkins and Papapanou (57) also suggested that preference was given to epidemiological publications of periodontitis in adolescents with radiographic marginal bone levels or proximal probing attachment loss, to avoid false periodontal pockets.

Three of the included studies reported aggressive periodontitis (25-27), which happens primarily in the young population and presents a rapid progression of inflammation. Since local irritants (DC and plaque) are rare with slight gum inflammation, aggressive periodontitis is easily overlooked at early stage (59). In 2017, European and American experts proposed to combine "chronic periodontitis" and "aggressive periodontitis" into "periodontitis" (60), removing the classification of aggressive periodontitis. Although the prevalence of aggressive periodontitis is not high, and the damage is severe. Rapid loss of periodontal tissues and even tooth loss are easily found during the development of the disease. Unfortunately, the disease progresses quickly and becomes rapidly serve with poor prognosis when young patients suffer pain and discomfort. It has a significant influence on chewing function, aesthetics. So, aggressive periodontitis emphasizes early detection, early diagnosis, prompt treatment, for avoiding irreversible damage to the periodontal tissue.

There were significant differences in the epidemic distribution of gingivitis among genders and the rural and urban population in China. A higher prevalence was observed in rural areas than urban. These phenomena may be associated with the unequal distribution of oral health services. In 2009, there were 286 dental hospitals in China. Only ten were built at the county level (61).

This may be attributed to the different oral hygiene habits of adolescents in rural and urban population, since good oral hygiene habits may contribute to the decline in the incidence of gingivitis $(62)$. Studies $(63,64)$ have reported that oral health practices and regular dental care habits were more frequent in urban areas than rural. Also, the estimated prevalence of gingivitis observed in boys $(51.0 \%)$ was significantly higher than in girls (48.7\%). Such discrepancies may be because of oral hygiene habits among boys and girls. Earlier studies $(65,66)$ have reported girls were considerate of their oral health and had a lower prevalence of gingivitis.

High heterogeneity in a meta-analysis from epidemiologic surveys are inevitable $(67,68)$. In this study, several factors might influence the heterogeneity: (I) the included studies had different sample sizes; (II) the sample populations had unique characteristics, including gender and area. Subgroup analysis for these unique characteristics, including gender and area, was conducted to explore the heterogeneity. After the subgroup analysis, the values of $\mathrm{I}^{2}$ reduced to $0 \%$ and $27.1 \%$ for the detection rate of $\mathrm{PD}$ $\geq 4 \mathrm{~mm}$, respectively; (III) bias in clinical examination also should be considered. For example, the diagnosis of PD was with the subjective judgment of the individual.

Some other limitations should also be considered in this study. First, studies that reported periodontal pockets status were insufficient, which may affect the accuracy of the result. Second, some studies only choose adolescents at a certain age, and others recruited adolescents in a broader age range. This difference may cause different sample sizes of the different age range. Third, The inspection methods of periodontitis were not standardized in all included studies, which was one of the main heterogeneities of this meta-analysis. To address this issue, a sensitivity analysis was conducted by eliminating each study to detect changes in conclusions of statistical analysis. After eliminating each study, the conclusions of statistical analysis are not influenced, which means the robustness of results. Finally, Publication bias in three indexes was observed, due to our selection criteria that only included peer-reviewed articles, but not other publication types such as "grey literature." The bias may also affect the estimates, even though we aimed to acquire all the relevant studies.

In conclusion, for adolescents, our results show a higher prevalence of gingivitis among the male and rural populations. Although the prevalence of periodontitis is $1 \%$, it may lead to periodontal tissue loss rapidly and even the loss of a tooth for adolescents. Hence, more emphasis should be placed on the periodontal health of adolescents to prevent periodontal disease. Higher-quality epidemiological surveys with standard examination criteria are needed.

\section{Acknowledgments}

Funding: The National Natural Science Fund supported 
this project (Grant No. 81700982), "Mechanism research on hypoxic upregulation of lncRNA-01126/HIF-1 $\alpha / \mathrm{MAPK}$ pathway in promoting periodontitis."

\section{Footnote}

Reporting Checklist: The authors have completed the PRISMA reporting checklist. Available at http://dx.doi. org/10.21037/apm-20-1919

Conflicts of Interest: All authors have completed the ICMJE uniform disclosure form (available at http://dx.doi. org/10.21037/apm-20-1919). The authors have no conflicts of interest to declare.

Ethical Statement: The authors are accountable for all aspects of the work in ensuring that questions related to the accuracy or integrity of any part of the work are appropriately investigated and resolved.

Open Access Statement: This is an Open Access article distributed in accordance with the Creative Commons Attribution-NonCommercial-NoDerivs 4.0 International License (CC BY-NC-ND 4.0), which permits the noncommercial replication and distribution of the article with the strict proviso that no changes or edits are made and the original work is properly cited (including links to both the formal publication through the relevant DOI and the license). See: https://creativecommons.org/licenses/by-nc-nd/4.0/.

\section{References}

1. Pei XY, He L, Ouyang, XY. Proposing a novel, three-level definition of periodontitis using probing depth, clinical attachment loss and bleeding on probing: analysis of a rural Chinese population. Chin J Dent Res 2017;20:89-96.

2. Yang H, Li X, Lei Z, et al. Epidemic trend of periodontal disease in elderly Chinese population, 1987-2015: a systematic review and meta-analysis Sci Rep. 2017;7:45000.

3. Tian W, Ma M, Zhang Y, et al. Investigation of oral health status of 3808 middle-aged and elder subjects in Yinchuan of Ningxia Hui autonomous region. Chin J Conservative Dent 2013;23:659-61.

4. Oh TJ, Eber R, Wang HL. Periodontal diseases in the child and adolescent. J Clin Periodontol 2002;29:400-10.

5. World Health Organization. Global Oral Health Data Bank. Geneva: WHO, 2001.

6. Jiang YF, Ju MF, Lin ZF, et al. A study on assessment standard for height and body weight of children aged 6 11 years in urban shanghai. Shanghai J Prev Med 2002;14:205-9.

7. Helm S, Petersen PE. Causal relation between malocclusion and periodontal health. Acta Odontol Scand 1989;47:223-8.

8. Zhang ZY. Orthodontic treatment of adult periodontal disease with malocclusion. World Latest Med Inf 2015;15:98-9.

9. Anil S, Hari S, Vijayakumar T. Periodontal conditions of a selected population in Trivandrum District, Kerala, India. Community Dent Oral Epidemiol 1990;18:325.

10. Miyazaki H, Hanada N, Andoh MI, et al. Periodontal disease prevalence in different age groups in Japan as assessed according to the CPITN. Community Dent Oral Epidemiol 1989;17:71-4.

11. Baelum V, Scheutz F. Periodontal diseases in Africa. Reg Anesth Pain Med 2021;46:31-34.

12. Vadiakas G, Oulis APCJ, Tsinidou K, et al. Oral hygiene and periodontal status of 12 and 15-year-old Greek adolescents. A national pathfinder survey. Eur Arch Paediatr Dent 2012;13:11-20.

13. El-Nadeef MA, Al HE, Hassab H, et al. National survey of the oral health of 12- and 15-year-old schoolchildren in the United Arab Emirates. East Mediterr Health J 2009;15:993-1004.

14. Murray JJ, Vernazza CR, Holmes RD. Forty years of national surveys: An overview of children's dental health from 1973-2013. Br Dent J 2015;219:281-5.

15. World Health Organization. Health for the world's adolescents: a second chance in the second decade: summary. World Health Organization. [cited 2017 Jan 22]. Available online: http://www.who.int/iris/ handle/10665/112750

16. National Bureau of Statistics of China. Tabulation on the 2010 population census of the People's Republic of China. [cited 2017 Jan 13]. Available online: http://www. stats.gov.cn

17. Bao L, Li Y, Bi Q, et al. Investigation and analysis of oral health status of 15 years old middle school students in Heilongjiang Province. Chin J Pract Stomatol 2013;6:432-4.

18. Jiang H, Du M, Huang W, et al. Sampling survey on periodontal health status of population in Hubei Province. J Oral Sci Res 2007;23:338-40.

19. Moher D, Liberati A, Tetzlaff J, et al. Preferred Reporting Items for Systematic Reviews and Meta-Analyses: The PRISMA Statement. PLoS Med 2009;6:e1000097. 
20. Cohen J. Weighted kappa: nominal scale agreement with provision for scaled disagreement or partial credit. Psychol Bull 1968;70:213-20.

21. von Elm E, Altman DG, Egger M, et al. The Strengthening the Reporting of Observational Studies in Epidemiology (STROBE) Statement: Guidelines for Reporting Observational Studies. PLoS Med 2007;4:e296.

22. The National Committee for Oral Health. In Second national epidemiological survey of oral health. In: Qi J. editor. Beijing: People's Medical Publishing House, 1998.

23. The National Committee for Oral Health. In Third national epidemiological survey of oral health. In: Qi XQ. editor. Beijing: People's Medical Publishing House, 2008.

24. The National Committee for Oral Health. In Forth national epidemiological survey of oral health. In: Wang X. editor. Beijing: People's Medical Publishing House, 2018.

25. Hu CZ, Liu GL, Li DY, et al. Juvenile periodontitis survey in 9548 middle school students at Huangpu District in Shanghai. Shanghai Kou Qiang Yi Xue 2002;11:300-2.

26. Wang Z, Qiu Q, Yang S, et al. Epidemiological study of Juvenile periodontitis, J Mod Stomatol 1990;4:171-2.

27. Tan T, Wu G, Guo L, et al. A survey of 1608 cases of juvenile periodontitis. J Harbin Med Univ 1995;29:522-3.

28. Li Y, Lu S, Dai J, et al. Epidemiological investigation of periodontal disease in urban and rural residents in Ningbo. Mod Pract Med 1997;9:7-9.

29. Cheng GY, Liu L, Zhang XL, et al. Prevalence and distribution of caries and periodontal disease among 15year old students in Dalian development area. Chin J Pract Stomatol 2010;3:404-6.

30. Li J, Hou B, Han X. Epidemiological investigation of periodontal disease among enterprise community population in Anyang. Henan J Prev Med 2002;13:339-40.

31. Zhang WX, Zhu YM, An G, et al. Epidemiology of dental caries and periodontal diseases in middle school students in Suzhou City. Shanghai Kou Qiang Yi Xue 2000;9:102-3.

32. Ding B. Epidemiological survey of caries and periodontal disease in Luzhou City. J Luzhou Med Coll 1983;4:1-4.

33. Wan H, Hu D, Liu D. Epidemiological survey of periodontal health among 660 students aged 12 13 years in five cities of Sichuan Province. West China J Stomatol 1994;12:73-5.

34. Tian M, Ma L, Yu X. A sampling survey of periodontal health among urban and rural residents in Guiyang. Guizhou Med J 2007;31:464-6.

35. Duan J, Niu Z, Wang S, et al. Prevalence rate of periodontal disease in middle school students in Beijing. Chin J Sch Doct 2000;14:145-6.

36. Lei L, Xu Z, Lin Y, et al. Analysis of periodontal health status of 15 year old students in Fujian Province. Strait J Prev Med 2006;12:34-6.

37. Lin JH, Li G. Prevalence of oral diseases of primary and middle school students in Chongqing. Chin J Sch Health 2004;25:30-1.

38. Wu FF, Zhao B, Ge XJ. Epidemiological survey on periodontal diseases among high-school students in Taiyuan. J Shanxi Med Univ 2006;37:258-60.

39. Liao Q, Qi X, Liao Z, et al. Oral health status of 4768 junior high school graduates in Xiangtan in 2003. J Mod Stomatol 2004;18:473-4.

40. Wu X, Wu L, Wei J. Investigation and analysis of dental diseases among middle school students in Jintan city in 2006. World Health Digest 2007;4:276.

41. Xie XW, Li P, Ding S, et al. Epidemiological survey of oral health status in population in Phosphorus Ming Area of Southern part in Guizhou Province. Mod Prev Med 2009;36:801-2.

42. Liu Y, Gu X, Lv Z. Investigation on dental caries, periodontal diseases and hygienic habits of primary and middle school students in Zoucheng City. Chinese Rural Health Serv Adm 2011;31:1169-70.

43. Yang Y, Li M. Oral health survey of 1518 junior high school graduates. Med Innovation China 2010;7:118-9.

44. Liu J, Liang M, Zhang P, et al. Investigation and analysis of periodontal health of middle school students in Shijiazhuang City. J Hebei Med Univ 2014;35:1214-6.

45. Bi QW, Zhao WW, Yin HW, et al. Analysis of oral health status in 18-year-students in Heilongjiang. J Med Res 2014;43:66-9.

46. Chen J, Lin Y, Wang N, et al. Investigation and analysis of questionnaire of dental caries and oral health status of 12 year old children in Haidian District. Hebei Med J 2017;39:1729-32.

47. Liu JG, Lin AY, Cai J. Investigation on dental disease status and oral health behavior analysis of 12-year-old pupils in Zhuhai city. New Clin Med in China 2019;12:385-8.

48. Lin L, Liu JW, Xiong LH, et al. Investigation and Analysis of knowledge and Behavior related to periodontal status of 12-year-old children in Guangzhou. South China Prev Med 2018;25:767-73.

49. Yin W, Yang YM, Chen H, et al. Oral health status in Sichuan province: findings from the oral health survey of Sichuan, 2015-2016. Int J Oral Sci 2017;9:10-5.

50. World Health Organization. Oral health Surveys: Basic 
methods; 1997.

51. Ainamo J, Barmes D, Beagrie G, et al. Development of the world health organization (WHO) community periodontal index of treatment needs (CPITN). Int Dent J 1982;32:281-91.

52. Petersen PE, Baez RJ, World Health Organization. Oral health surveys: basic methods; 2013.

53. Radnai M, Gorzó I, Urbán E, et al. Possible association between mother's periodontal status and preterm delivery. J Clin Periodontol 2006;33:791-6.

54. Australian Institute of Health and Welfare. Oral health and dental care in Australia: key facts and figures trends 2014. Canberra: Australian Institute of Health and Welfare, 2014. [cited 2017 Dec 18]. Available online: www. aihw.gov.au/reports/dental-oral-health/key-facts-figurestrends-2014

55. Campus G, Cagetti MG, Senna A, et al. Differences in oral health among Italian adolescents related to the type of secondary school attended. Oral Health Prev Dent 2009;7:323-30.

56. Corbet EF, Zee KY, Lo EC. Periodontal diseases in Asia and Oceania. Periodontol 2000 2002;29:122-52.

57. Chen X, Wang L, He Z, et al. Effects of xipayi mouth rinse combined with minocycline on localized aggressive periodontitis' therapeutic effect and the levels of CRP, TNF- $\alpha$, IL-6 in serum. Ann Palliat Med 2020;9:3410-7.

58. Dye BA, Tan S, Smith V. Trends in oral health status: United States, 1988-1994 and 1999-2004. Vital Health Stat 11 2007;248:1-92.

59. Armitage GC, Cullinan MP. Comparison of the clinical features of chronic and aggressive periodontitis. Periodontol 2000 2010;53:12-27.

60. Meng HX. 2018 world new classification of periodontal

Cite this article as: Xiao L, Karapen K, Dong S, Yang H, Zhang X. Epidemiology of periodontal disease in adolescents in mainland China, 1983-2020: a systematic review and metaanalysis. Ann Palliat Med 2021;10(1):45-60. doi: 10.21037/apm20-1919 and peri-implant diseases and condition. Zhonghua Kou Qiang Yi Xue Za Zhi 2019;54:73-8.

61. Lin HC, Zhang Y. Oral health care system in Chinese Mainland. J Am Coll Dent 2007;74:11-3.

62. Xuan Z, Zhang C, Wang J. Research on correlation between oral health habits and prevalence rate of gingivitis in children. China Health Ind 2016;13:26-8.

63. Zhu L, Petersen PE, Wang HY, et al. Oral health knowledge, attitudes and behavior of children and adolescents in China. Int Dent J 2003;53:289-98.

64. Wei Q, Han X. A survey of the knowledge-attitudebehavior about oral health in urban and rural middle school students aged 12-15. Anhui Med Pharm J 2017;21:841-3.

65. Hunter ML, Newcombe R, Richmond S, et al. The Cardiff dental survey: oral hygiene and gingival health between the ages of 11-12 and 30-31 years. Br Dent J 2007;203:E23; discussion 650-1.

66. Taani DQ. Trends in oral hygiene, gingival status and dental caries experience in 13-14-year-old Jordanian school children between 1993 and 1999. Int Dent J 2001;51:447-50.

67. Mitchell AJ, Chan M, Bhatti H, et al. Prevalence of depression, anxiety, and adjustment disorder in oncological, haematological, and palliative-care settings: a meta-analysis of 94 interview-based studies. Lancet Oncol 2011;12:160-74.

68. Winsper C, Ganapathy R, Marwaha S, et al. A systematic review and meta-regression analysis of aggression during the first episode of psychosis. Acta Psychiatr Scand 2013;128:413-21.

(English Language Editor: J. Chapnick) 
Table S1 STROBE Statement—checklist of items that should be included in reports of observational studies

\begin{tabular}{|c|c|c|}
\hline & Item No. & Recommendation \\
\hline \multirow[t]{2}{*}{ Title and abstract } & 1 & (a) Indicate the study's design with a commonly used term in the title or the abstract \\
\hline & & (b) Provide in the abstract an informative and balanced summary of what was done and what was found \\
\hline \multicolumn{3}{|l|}{ Introduction } \\
\hline Background/rationale & 2 & Explain the scientific background and rationale for the investigation being reported \\
\hline Objectives & 3 & State specific objectives, including any prespecified hypotheses \\
\hline \multicolumn{3}{|l|}{ Methods } \\
\hline Study design & 4 & Present key elements of study design early in the paper \\
\hline Setting & 5 & Describe the setting, locations, and relevant dates, including periods of recruitment, exposure, follow-up, and data collection \\
\hline \multirow[t]{3}{*}{ Participants } & 6 & $\begin{array}{l}\text { (a) Cohort study-Give the eligibility criteria, and the sources and methods of selection of participants. Describe methods of follow-up } \\
\text { Case-control study - Give the eligibility criteria, and the sources and methods of case ascertainment and control selection. Give the rationale for } \\
\text { the choice of cases and controls }\end{array}$ \\
\hline & & Cross-sectional study - Give the eligibility criteria, and the sources and methods of selection of participants \\
\hline & & $\begin{array}{l}\text { (b) Cohort study-For matched studies, give matching criteria and number of exposed and unexposed } \\
\text { Case-control study - For matched studies, give matching criteria and the number of controls per case }\end{array}$ \\
\hline Variables & 7 & Clearly define all outcomes, exposures, predictors, potential confounders, and effect modifiers. Give diagnostic criteria, if applicable \\
\hline \multicolumn{2}{|l|}{ Data sources/measurement $8^{*}$} & $\begin{array}{l}\text { For each variable of interest, give sources of data and details of methods of assessment (measurement). Describe comparability of assessment } \\
\text { methods if there is more than one group }\end{array}$ \\
\hline Bias & 9 & Describe any efforts to address potential sources of bias \\
\hline Study size & 10 & Explain how the study size was arrived at \\
\hline Quantitative variables & 11 & Explain how quantitative variables were handled in the analyses. If applicable, describe which groupings were chosen and why \\
\hline \multirow[t]{7}{*}{ Statistical methods } & 12 & (a) Describe all statistical methods, including those used to control for confounding \\
\hline & & (b) Describe any methods used to examine subgroups and interactions \\
\hline & & (c) Explain how missing data were addressed \\
\hline & & (d) Cohort study - If applicable, explain how loss to follow-up was addressed \\
\hline & & Case-control study - If applicable, explain how matching of cases and controls was addressed \\
\hline & & Cross-sectional study - If applicable, describe analytical methods taking account of sampling strategy \\
\hline & & (e) Describe any sensitivity analyses \\
\hline
\end{tabular}

Results

Participants

Descriptive data

Outcome data

Main results

Other analyses

Discussion

Key results

Limitations

Interpretation

Generalisability

Other information

Funding (a) Report numbers of individuals at each stage of study - eg numbers potentially eligible, examined for eligibility, confirmed eligible, included in the study, completing follow-up, and analysed

(b) Give reasons for non-participation at each stage

(c) Consider use of a flow diagram

$14^{\star} \quad$ (a) Give characteristics of study participants (eg demographic, clinical, social) and information on exposures and potential confounders

(b) Indicate number of participants with missing data for each variable of interest

(c) Cohort study-Summarise follow-up time (eg, average and total amount)

$15^{\star} \quad$ Cohort study-Report numbers of outcome events or summary measures over time

Case-control study-Report numbers in each exposure category, or summary measures of exposure

Cross-sectional study-Report numbers of outcome events or summary measures

16 (a) Give unadjusted estimates and, if applicable, confounder-adjusted estimates and their precision (eg, 95\% confidence interval). Make clear which confounders were adjusted for and why they were included

(b) Report category boundaries when continuous variables were categorized

(c) If relevant, consider translating estimates of relative risk into absolute risk for a meaningful time period

Report other analyses done-eg analyses of subgroups and interactions, and sensitivity analyses

18 Summarise key results with reference to study objectives

19 Discuss limitations of the study, taking into account sources of potential bias or imprecision. Discuss both direction and magnitude of any potential bias

20 Give a cautious overall interpretation of results considering objectives, limitations, multiplicity of analyses, results from similar studies, and other relevant evidence

21 Discuss the generalisability (external validity) of the study results

Give the source of funding and the role of the funders for the present study and, if applicable, for the original study on which the present article is based

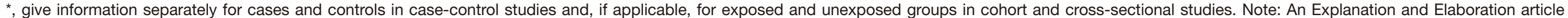

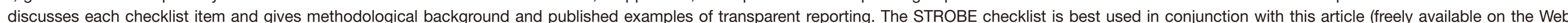

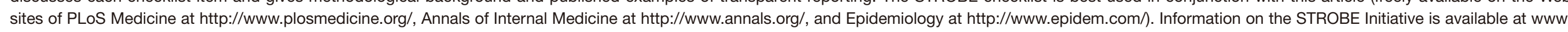
strobe-statement.org. 
Table S2 Agreement among authors on titles and abstracts [kappa coefficients]

\begin{tabular}{lccc}
\hline \multirow{2}{*}{ Author1 } & \multicolumn{3}{c}{ Author2 } \\
\cline { 2 - 4 } & Exclusion & Inclusion & Total \\
\hline Exclusion & 2,530 & 41 & 2,571 \\
Inclusion & 33 & 268 & 301 \\
Total & 2,563 & 309 & 2,872 \\
\hline
\end{tabular}

$\mathrm{K} 1=0.864139$.
Table S3 Agreement among authors on full-text analysis [kappa coefficients]

\begin{tabular}{lccc}
\hline \multirow{2}{*}{ Author1 } & \multicolumn{3}{c}{ Author2 } \\
\cline { 2 - 4 } & Exclusion & Inclusion & Total \\
\hline Exclusion & 725 & 7 & 732 \\
Inclusion & 5 & 26 & 31 \\
Total & 730 & 33 & 763 \\
\hline K1=0.804278. & & &
\end{tabular}


Table S4 Quality assessment of included 30 studies

\begin{tabular}{|c|c|c|c|c|c|c|c|c|c|c|c|c|c|c|c|c|c|c|c|c|c|c|c|c|c|c|c|c|c|c|c|c|c|}
\hline \multirow{2}{*}{ Study } & \multicolumn{2}{|c|}{ Title \& abstract } & \multicolumn{2}{|c|}{ Introduction } & \multicolumn{13}{|c|}{ Methods } & \multicolumn{10}{|c|}{ Results } & \multicolumn{4}{|c|}{ Discussion } & \multirow{2}{*}{$\begin{array}{c}\text { Other information } \\
22\end{array}$} & \multirow{2}{*}{ Number of $Y$} \\
\hline & $1 \mathrm{a}$ & $1 \mathrm{~b}$ & 2 & 3 & 4 & 5 & 6 & 7 & 8 & 9 & 10 & 11 & $12 a$ & $12 b$ & $12 \mathrm{c}$ & $12 \mathrm{~d}$ & $12 \mathrm{e}$ & $13 a$ & $13 b$ & $13 c$ & $14 a$ & $14 \mathrm{~b}$ & 15 & $16 a$ & $16 \mathrm{~b}$ & $16 c$ & 17 & 18 & 19 & 20 & 21 & & \\
\hline Ding, 1983 & $\mathrm{Y}$ & $\mathrm{Y}$ & $\mathrm{Y}$ & Y & $\mathrm{Y}$ & Y & $\mathrm{Y}$ & $\mathrm{Y}$ & $\mathrm{N}$ & $\mathrm{Y}$ & $\mathrm{N}$ & $\mathrm{Y}$ & $\mathrm{N}$ & $\mathrm{Y}$ & $\mathrm{Y}$ & $\mathrm{Y}$ & $\mathrm{N}$ & $\mathrm{Y}$ & $\mathrm{Y}$ & $\mathrm{Y}$ & $\mathrm{Y}$ & $\mathrm{Y}$ & $\mathrm{Y}$ & $\mathrm{Y}$ & $\mathrm{Y}$ & $\mathrm{Y}$ & $\mathrm{Y}$ & $\mathrm{Y}$ & $\mathrm{Y}$ & $\mathrm{Y}$ & $\mathrm{Y}$ & $\mathrm{Y}$ & 28 \\
\hline Wang et al., 1990 & $\mathrm{Y}$ & $\mathrm{N}$ & $\mathrm{Y}$ & $\mathrm{N}$ & $\mathrm{Y}$ & $\mathrm{Y}$ & $\mathrm{Y}$ & $\mathrm{Y}$ & $\mathrm{Y}$ & $\mathrm{Y}$ & $\mathrm{N}$ & $\mathrm{Y}$ & $\mathrm{Y}$ & $\mathrm{N}$ & $\mathrm{Y}$ & Y & $\mathrm{Y}$ & $\mathrm{Y}$ & $\mathrm{Y}$ & $\mathrm{Y}$ & $\mathrm{Y}$ & $\mathrm{Y}$ & $\mathrm{Y}$ & $\mathrm{Y}$ & $\mathrm{N}$ & $\mathrm{Y}$ & $\mathrm{N}$ & $\mathrm{Y}$ & $\mathrm{Y}$ & $\mathrm{Y}$ & $\mathrm{Y}$ & $\mathrm{Y}$ & 25 \\
\hline Wan et al., 1994 & $\mathrm{Y}$ & $\mathrm{Y}$ & $\mathrm{Y}$ & $\mathrm{Y}$ & $\mathrm{Y}$ & Y & $\mathrm{Y}$ & $\mathrm{Y}$ & $\mathrm{Y}$ & $\mathrm{Y}$ & $\mathrm{N}$ & $\mathrm{Y}$ & $\mathrm{N}$ & $\mathrm{Y}$ & $\mathrm{N}$ & $\mathrm{Y}$ & $\mathrm{Y}$ & $\mathrm{Y}$ & $\mathrm{Y}$ & $\mathrm{Y}$ & $\mathrm{Y}$ & $\mathrm{Y}$ & $\mathrm{Y}$ & $\mathrm{N}$ & $\mathrm{Y}$ & $\mathrm{N}$ & Y & $\mathrm{Y}$ & $\mathrm{Y}$ & $\mathrm{Y}$ & $\mathrm{Y}$ & $\mathrm{Y}$ & 27 \\
\hline Tan et al., 1995 & Y & $\mathrm{Y}$ & $\mathrm{Y}$ & $\mathrm{N}$ & $\mathrm{Y}$ & $\mathrm{Y}$ & $\mathrm{Y}$ & $\mathrm{Y}$ & Y & $\mathrm{Y}$ & $\mathrm{N}$ & $\mathrm{Y}$ & $\mathrm{Y}$ & $\mathrm{Y}$ & $\mathrm{N}$ & Y & $\mathrm{N}$ & $\mathrm{Y}$ & $\mathrm{Y}$ & $\mathrm{Y}$ & $\mathrm{Y}$ & $\mathrm{Y}$ & $\mathrm{Y}$ & Y & Y & N & $\mathrm{Y}$ & Y & $\mathrm{N}$ & Y & $Y$ & Y & 26 \\
\hline Li et al., 1997 & Y & Y & $\mathrm{Y}$ & Y & Y & $\mathrm{Y}$ & $\mathrm{Y}$ & Y & Y & $\mathrm{Y}$ & $Y$ & Y & Y & Y & $\mathrm{N}$ & $\mathrm{N}$ & $\mathrm{N}$ & $\mathrm{Y}$ & $\mathrm{Y}$ & Y & Y & $\mathrm{Y}$ & Y & $\mathrm{N}$ & $\mathrm{Y}$ & Y & Y & Y & $\mathrm{N}$ & Y & $\mathrm{Y}$ & Y & 27 \\
\hline Duan et al., 2000 & Y & Y & $Y$ & Y & $\mathrm{Y}$ & Y & $Y$ & $\mathrm{Y}$ & $\mathrm{Y}$ & Y & $Y$ & Y & $\mathrm{N}$ & Y & $\mathrm{N}$ & Y & $\mathrm{N}$ & Y & $\mathrm{Y}$ & Y & Y & $\mathrm{Y}$ & $\mathrm{Y}$ & $\mathrm{N}$ & Y & Y & $\mathrm{N}$ & Y & $\mathrm{Y}$ & Y & $Y$ & Y & 27 \\
\hline Tian et al., 2007 & $\mathrm{Y}$ & $\mathrm{N}$ & $\mathrm{N}$ & $\mathrm{Y}$ & $\mathrm{Y}$ & Y & Y & $\mathrm{Y}$ & Y & Y & Y & $\mathrm{Y}$ & Y & $\mathrm{N}$ & $\mathrm{Y}$ & Y & $\mathrm{N}$ & $\mathrm{Y}$ & $\mathrm{Y}$ & $\mathrm{Y}$ & Y & $\mathrm{Y}$ & Y & $\mathrm{N}$ & $\mathrm{N}$ & $\mathrm{Y}$ & Y & Y & $\mathrm{N}$ & Y & $\mathrm{Y}$ & Y & 25 \\
\hline Hu et al., 2002 & Y & Y & Y & Y & Y & Y & Y & Y & Y & $\mathrm{Y}$ & $\mathrm{N}$ & Y & $\mathrm{N}$ & Y & $\mathrm{Y}$ & Y & $\mathrm{N}$ & Y & Y & $\mathrm{Y}$ & Y & $\mathrm{Y}$ & Y & $\mathrm{N}$ & Y & Y & $\mathrm{N}$ & Y & $\mathrm{N}$ & Y & $\mathrm{Y}$ & Y & 26 \\
\hline Li et al., 2002 & $\mathrm{Y}$ & Y & Y & Y & Y & Y & Y & Y & Y & Y & $\mathrm{N}$ & $\mathrm{Y}$ & $\mathrm{N}$ & Y & $\mathrm{N}$ & $\mathrm{N}$ & Y & Y & Y & Y & Y & $\mathrm{Y}$ & Y & $\mathrm{N}$ & Y & $\mathrm{Y}$ & $\mathrm{N}$ & Y & $\mathrm{N}$ & $\mathrm{Y}$ & $\mathrm{Y}$ & Y & 25 \\
\hline Lei et al., 2006 & Y & Y & $\mathrm{Y}$ & Y & $\mathrm{Y}$ & Y & $\mathrm{Y}$ & $\mathrm{Y}$ & $\mathrm{Y}$ & $\mathrm{Y}$ & $\mathrm{Y}$ & Y & Y & $\mathrm{N}$ & $\mathrm{N}$ & $\mathrm{N}$ & $\mathrm{N}$ & $\mathrm{Y}$ & $\mathrm{Y}$ & $\mathrm{Y}$ & Y & Y & $\mathrm{Y}$ & $\mathrm{N}$ & Y & Y & Y & $\mathrm{Y}$ & $\mathrm{N}$ & Y & $\mathrm{Y}$ & Y & 26 \\
\hline Lin \& Li., 2004 & Y & $\mathrm{Y}$ & Y & Y & $\mathrm{Y}$ & Y & $\mathrm{Y}$ & Y & Y & Y & Y & Y & Y & Y & $\mathrm{Y}$ & $\mathrm{N}$ & $\mathrm{N}$ & Y & Y & $\mathrm{Y}$ & Y & $\mathrm{Y}$ & Y & $\mathrm{Y}$ & $\mathrm{N}$ & Y & Y & Y & $\mathrm{N}$ & Y & $\mathrm{Y}$ & Y & 28 \\
\hline Wu et al., 2006 & $\mathrm{Y}$ & $\mathrm{Y}$ & $Y$ & $\mathrm{Y}$ & Y & Y & $Y$ & $\mathrm{Y}$ & $\mathrm{Y}$ & $Y$ & $Y$ & $\mathrm{Y}$ & $\mathrm{N}$ & $\mathrm{Y}$ & $\mathrm{Y}$ & $\mathrm{N}$ & $\mathrm{N}$ & $\mathrm{Y}$ & $\mathrm{Y}$ & Y & $\mathrm{Y}$ & $\mathrm{Y}$ & $\mathrm{Y}$ & $\mathrm{N}$ & $\mathrm{Y}$ & $\mathrm{Y}$ & $\mathrm{Y}$ & $\mathrm{Y}$ & $\mathrm{Y}$ & $\mathrm{Y}$ & $\mathrm{Y}$ & Y & 28 \\
\hline Liao et al., 2004 & Y & Y & Y & Y & Y & Y & $\mathrm{Y}$ & Y & Y & Y & Y & Y & Y & $\mathrm{N}$ & $\mathrm{N}$ & $\mathrm{N}$ & Y & Y & $\mathrm{Y}$ & Y & Y & Y & Y & Y & $\mathrm{N}$ & Y & Y & Y & $\mathrm{N}$ & Y & Y & Y & 27 \\
\hline Jiang et al., 2007 & $\mathrm{Y}$ & Y & $Y$ & Y & Y & Y & $\mathrm{Y}$ & Y & $\mathrm{Y}$ & $\mathrm{Y}$ & $Y$ & $\mathrm{Y}$ & Y & $\mathrm{N}$ & $\mathrm{N}$ & Y & $\mathrm{Y}$ & $\mathrm{Y}$ & $\mathrm{Y}$ & Y & Y & $\mathrm{Y}$ & Y & Y & $\mathrm{N}$ & $\mathrm{Y}$ & Y & Y & Y & $\mathrm{Y}$ & $Y$ & Y & 29 \\
\hline Xie et al., 2009 & $\mathrm{Y}$ & Y & $\mathrm{Y}$ & Y & Y & $\mathrm{Y}$ & $\mathrm{Y}$ & Y & Y & $\mathrm{Y}$ & $\mathrm{Y}$ & Y & Y & Y & $\mathrm{N}$ & Y & $\mathrm{N}$ & $\mathrm{Y}$ & $\mathrm{Y}$ & $\mathrm{Y}$ & $\mathrm{Y}$ & Y & Y & $\mathrm{N}$ & $\mathrm{N}$ & Y & Y & $\mathrm{Y}$ & $\mathrm{N}$ & Y & $\mathrm{Y}$ & Y & 27 \\
\hline Yang \& Li, 2010 & Y & Y & Y & Y & Y & Y & Y & Y & Y & Y & Y & Y & Y & $\mathrm{N}$ & $\mathrm{N}$ & $\mathrm{N}$ & $\mathrm{N}$ & Y & Y & Y & Y & Y & Y & Y & Y & $\mathrm{N}$ & Y & Y & $\mathrm{N}$ & Y & $Y$ & Y & 26 \\
\hline Cheng et al., 2010 & Y & Y & $\mathrm{Y}$ & Y & Y & $\mathrm{Y}$ & $\mathrm{Y}$ & $\mathrm{Y}$ & Y & $\mathrm{Y}$ & $\mathrm{Y}$ & Y & Y & $\mathrm{N}$ & Y & $\mathrm{N}$ & Y & $\mathrm{Y}$ & Y & Y & $\mathrm{Y}$ & $\mathrm{Y}$ & Y & $\mathrm{N}$ & Y & $\mathrm{N}$ & $\mathrm{N}$ & Y & $\mathrm{Y}$ & Y & $\mathrm{Y}$ & Y & 27 \\
\hline Liu et al., 2011 & Y & $\mathrm{Y}$ & $\mathrm{Y}$ & Y & $\mathrm{Y}$ & $\mathrm{Y}$ & $\mathrm{Y}$ & $\mathrm{Y}$ & $\mathrm{N}$ & $\mathrm{N}$ & $\mathrm{N}$ & Y & Y & $\mathrm{N}$ & $\mathrm{Y}$ & $\mathrm{Y}$ & $\mathrm{Y}$ & $\mathrm{Y}$ & $\mathrm{Y}$ & $\mathrm{Y}$ & $\mathrm{Y}$ & $\mathrm{Y}$ & Y & $\mathrm{N}$ & $\mathrm{Y}$ & Y & $\mathrm{N}$ & Y & $\mathrm{N}$ & $\mathrm{Y}$ & $\mathrm{Y}$ & Y & 25 \\
\hline Bao et al., 2013 & $\mathrm{Y}$ & $\mathrm{Y}$ & Y & Y & $\mathrm{Y}$ & Y & $\mathrm{Y}$ & $\mathrm{Y}$ & $\mathrm{Y}$ & $\mathrm{Y}$ & $\mathrm{Y}$ & $\mathrm{Y}$ & $\mathrm{Y}$ & $\mathrm{Y}$ & $\mathrm{N}$ & $\mathrm{N}$ & $\mathrm{N}$ & $\mathrm{Y}$ & $\mathrm{Y}$ & $\mathrm{Y}$ & $\mathrm{Y}$ & $\mathrm{Y}$ & $\mathrm{Y}$ & $\mathrm{N}$ & $\mathrm{Y}$ & $\mathrm{N}$ & Y & $\mathrm{Y}$ & $\mathrm{N}$ & $\mathrm{Y}$ & $\mathrm{Y}$ & $\mathrm{Y}$ & 26 \\
\hline Bi et al., 2014 & $\mathrm{Y}$ & $\mathrm{Y}$ & $\mathrm{Y}$ & $\mathrm{Y}$ & Y & $\mathrm{Y}$ & $\mathrm{Y}$ & $\mathrm{Y}$ & $\mathrm{N}$ & $\mathrm{Y}$ & $\mathrm{Y}$ & $\mathrm{Y}$ & $\mathrm{N}$ & $\mathrm{N}$ & $\mathrm{Y}$ & $\mathrm{Y}$ & $\mathrm{N}$ & $\mathrm{Y}$ & $\mathrm{Y}$ & $\mathrm{Y}$ & $\mathrm{Y}$ & $\mathrm{Y}$ & $\mathrm{Y}$ & $\mathrm{N}$ & $\mathrm{Y}$ & $\mathrm{Y}$ & $\mathrm{Y}$ & $\mathrm{Y}$ & $\mathrm{N}$ & $\mathrm{Y}$ & $\mathrm{Y}$ & Y & 26 \\
\hline Liu et al., 2014 & $\mathrm{Y}$ & $\mathrm{Y}$ & $\mathrm{Y}$ & $\mathrm{Y}$ & $\mathrm{Y}$ & $\mathrm{Y}$ & $\mathrm{Y}$ & $\mathrm{Y}$ & $\mathrm{Y}$ & $\mathrm{Y}$ & $\mathrm{Y}$ & Y & Y & $\mathrm{Y}$ & $\mathrm{N}$ & $\mathrm{N}$ & $\mathrm{N}$ & $\mathrm{Y}$ & $\mathrm{Y}$ & $\mathrm{Y}$ & $\mathrm{Y}$ & $\mathrm{Y}$ & $\mathrm{Y}$ & $\mathrm{N}$ & $\mathrm{N}$ & Y & $\mathrm{N}$ & Y & $\mathrm{N}$ & Y & $\mathrm{Y}$ & Y & 25 \\
\hline Chen et al., 2017 & Y & Y & Y & Y & Y & Y & Y & Y & Y & Y & Y & Y & $\mathrm{N}$ & $\mathrm{N}$ & $\mathrm{N}$ & Y & $\mathrm{N}$ & Y & Y & Y & Y & $\mathrm{Y}$ & Y & Y & $\mathrm{N}$ & Y & $\mathrm{N}$ & Y & $\mathrm{N}$ & Y & $\mathrm{Y}$ & Y & 25 \\
\hline Yin et al., 2017 & $\mathrm{Y}$ & $\mathrm{Y}$ & $Y$ & Y & Y & $Y$ & $Y$ & Y & $\mathrm{N}$ & Y & $Y$ & $\mathrm{Y}$ & $\mathrm{N}$ & $\mathrm{N}$ & Y & Y & $\mathrm{N}$ & $\mathrm{Y}$ & Y & Y & Y & $\mathrm{Y}$ & Y & $\mathrm{N}$ & Y & $\mathrm{Y}$ & Y & Y & $\mathrm{N}$ & $\mathrm{Y}$ & $Y$ & Y & 26 \\
\hline $\mathrm{NCOH}, 1998$ & $\mathrm{Y}$ & Y & $\mathrm{Y}$ & Y & $\mathrm{Y}$ & Y & $\mathrm{Y}$ & $\mathrm{Y}$ & $\mathrm{Y}$ & $\mathrm{Y}$ & $\mathrm{Y}$ & Y & Y & Y & $\mathrm{Y}$ & Y & Y & $\mathrm{Y}$ & $\mathrm{Y}$ & Y & Y & $\mathrm{Y}$ & Y & Y & Y & Y & Y & Y & $\mathrm{Y}$ & Y & $\mathrm{Y}$ & Y & 32 \\
\hline $\mathrm{NCOH}, 2009$ & Y & Y & Y & Y & $\mathrm{Y}$ & Y & $\mathrm{Y}$ & Y & Y & $\mathrm{Y}$ & Y & Y & Y & Y & $\mathrm{Y}$ & Y & $\mathrm{Y}$ & Y & $\mathrm{Y}$ & Y & Y & $\mathrm{Y}$ & Y & $\mathrm{Y}$ & Y & Y & Y & Y & Y & Y & $\mathrm{Y}$ & Y & 32 \\
\hline $\mathrm{NCOH}, 2018$ & Y & Y & Y & Y & $\mathrm{Y}$ & $\mathrm{Y}$ & Y & Y & Y & Y & Y & Y & Y & Y & Y & Y & $\mathrm{Y}$ & Y & Y & Y & Y & Y & Y & $\mathrm{Y}$ & $\mathrm{Y}$ & Y & Y & $\mathrm{Y}$ & $\mathrm{Y}$ & Y & $\mathrm{Y}$ & Y & 32 \\
\hline Lin et al., 2018 & Y & Y & Y & $\mathrm{N}$ & Y & Y & $\mathrm{Y}$ & Y & Y & Y & $\mathrm{N}$ & Y & $\mathrm{N}$ & Y & Y & Y & $\mathrm{N}$ & Y & $\mathrm{Y}$ & Y & Y & Y & $\mathrm{Y}$ & Y & $\mathrm{N}$ & Y & Y & Y & $\mathrm{Y}$ & Y & $\mathrm{Y}$ & Y & 27 \\
\hline Liu et al., 2019 & $\mathrm{Y}$ & $\mathrm{Y}$ & $\mathrm{Y}$ & $\mathrm{N}$ & $\mathrm{Y}$ & Y & Y & Y & $\mathrm{Y}$ & Y & $\mathrm{Y}$ & Y & $\mathrm{N}$ & $\mathrm{Y}$ & $\mathrm{Y}$ & $\mathrm{Y}$ & $\mathrm{N}$ & $\mathrm{Y}$ & Y & $\mathrm{Y}$ & $Y$ & $\mathrm{Y}$ & $\mathrm{Y}$ & $\mathrm{Y}$ & $\mathrm{N}$ & $\mathrm{Y}$ & $\mathrm{Y}$ & $\mathrm{Y}$ & $Y$ & $\mathrm{Y}$ & $Y$ & $\mathrm{Y}$ & 28 \\
\hline
\end{tabular}

$\mathrm{Y}$, yes; $\mathrm{N}, \mathrm{no} ; \mathrm{NCOH}$, National Committee for Oral Health. 

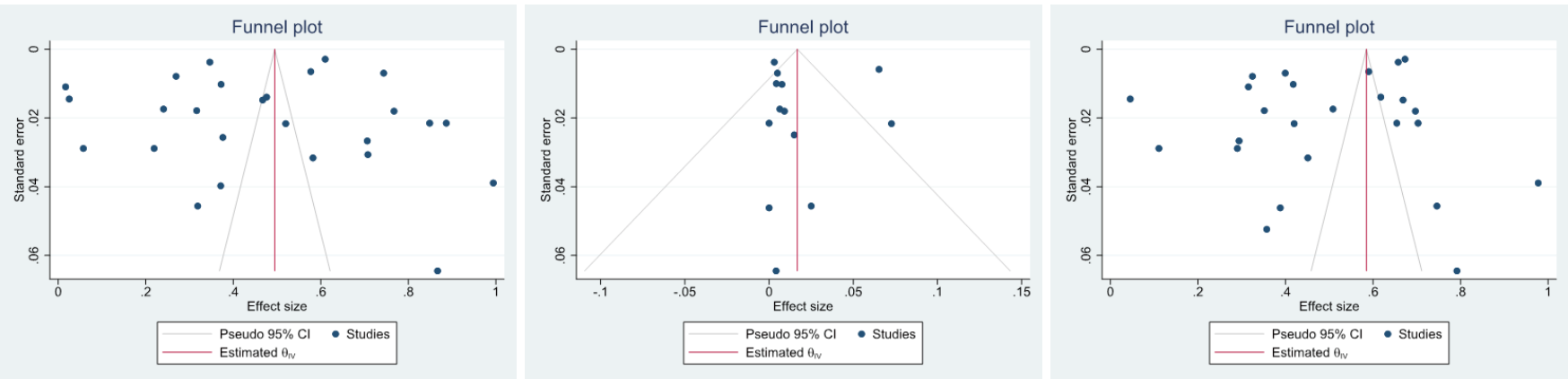

Figure S1 Funnel plots for studies. 